\title{
Impacts of COVID-19 Pandemic on Dairy and Poultry Sectors: Future Guidelines for Overcoming these Effects
}

\section{Hamza Jawad ${ }^{1 *}$, Riaz Ahmed Gul', Nasir Iqbal ${ }^{2}$, Talha Safdar', Muhammad Ammun Bashir ${ }^{1}$, Hafiz Muhammad Mubashar Ali ${ }^{1}$, Muhammad Tasadaq Hameed ${ }^{1}$ and Ateeq Iqbal $^{1}$}

${ }^{1}$ Faculty of Veterinary and Animal Sciences, The Islamia University of Bahawalpur, Bahawalpur, Pakistan

${ }^{2}$ Department of Veterinary Surgery and Pet Sciences, University of Veterinary and Animal Sciences, Lahore, Punjab, Pakistan

*Corresponding Author: Hamza Jawad, Faculty of Veterinary and Animal

Sciences, The Islamia University of Bahawalpur, Bahawalpur, Punjab, Pakistan.
Received: November 24, 2020

Published: December 09, 2020

(C) All rights are reserved by Hamza Jawad., et al.

\begin{abstract}
Coronavirus disease (COVID-19) has affected the current food system globally. Like the health system, the stability of the food system should be a priority during any pandemic and associated lockdowns. COVID-19 pandemic is severely affecting food safety, food security and overall food chain. Livestock sector is a major source of animal food products and by-products. The economics of the processed milk and meat industries are being severely affected during the lockdown. Due to the lack of transportation facilities, livestock products are not available to everyone. Several issues are faced by agriculture, dairy and poultry farmers during this pandemic. This review article highlights the importance of incorporating new technologies into the livestock sector to lessen the undesirable effects of the pandemics on the animal-based food industry and farming. Animal production and disease resistance must be improved through breeding and genetics discussed in this article below. The role of veterinarians in maintaining animal health and preventing zoonotic diseases during infectious diseases has also been highlighted. Digitalization and implementation of new policies in the livestock and poultry sector regarding the telemedicine, online sale and purchase of animals and their products is inevitable especially in underdeveloped countries. Such guidelines could help the state overcome crises related to food, livestock and human health in pandemics.
\end{abstract}

Keywords: COVID-19; Livestock Sector; Telemedicine; Meat and Milk; Zoonosis

\section{Introduction}

In March, 2020 the World Health Organization announced that COVID-19 has now become a global issue. Countries around the world have devised different policies to prevent the spread of this pandemic via lockdowns, inter-regional traffic restrictions, prohibition of various activities like religious and political gatherings, strict implementation of Standard operating procedures (SOPs) and large-scale COVID-19 testing [1]. According to Djalante., et al. 2020 government has established a community health emergency in the framework of accelerating the handling of COVID-19 through Presidential Decree No. 11 of 2020 and Government Regulation
No. 21 of 2020 [2]. The pandemic not only has a negative impact on the health sector but also threatens various sectors such as the food, economy, society, education and many others [3]. Faced with the current situation, scientists and stakeholders have predicted that the current pandemic will have both short and long-term effects. Livestock sector that, is predicted to attain the Sustainable Development Goals (SDGs) in 2030, cannot escape the negative effects of this global crisis [4]. Not only the impacts mentioned earlier, but also the lack of animal-derived food, is one of the challenges and risks of the current COVID-19 pandemic and post-pandemic rehabilitation period [5]. Numerous fields related to animal-based 
food supplementation have been suspended during the pandemic because production processes, distribution and consumption are not functioning normally [6,7]. Data from various online articles, journals, and books has been reviewed and summarized. In particular, this review article presents that how the COVID-19 lockdown affects the actual animal origin food supply and how we can optimize these effects especially related to food resources management during future pandemics.

\section{Importance of stable livestock sector during pandemics}

Food security (with new concepts nutrition security) is primary task of every state. Like agriculture sector, livestock sector has its great importance in providing food to all of us from animals (meant, milk \& by-products) and birds (meat and eggs). The importance of Agro-industrial complex can never be ignored especially during pandemics. Similarly, significance of livestock domain is also crucial. Balance between food sources and population requirement is much necessary to provide sufficient food supplies during lockdown situations $[8,9]$. As urbanization is increasing the consumption of livestock products is increasing unceasingly. Commercial livestock and poultry farms with processing units are somewhere present in big cities but not in every city. Many cities are facing huge shortage of livestock products like milk and meat during pandemics and lockdowns $[10,11]$.

Numerous fields related to animal-based food supplementation have been suspended during the pandemic so that production processes, distribution and consumption are not functioning normally $[7,12,13]$. In addition to the effects of COVID-19, the ability to produce many animal-derived products that have not yet met the requirements, the risk factor for antibiotic resistance in meat and milk, causes a shortage of food for humans. According to One Health concept, animal health is very important for keeping human healthy $[14,15]$.

\section{Optimization of food services during pandemics}

The facts obtained from already conducted research studies about veterinary hygiene and medicine can help a lot in boosting up the production of livestock products. By using such scientific data, we want to get the minimum cost of livestock products by optimizing the parameters of the climate and maintaining production mechanisms up to the optimum level [16]. Effective solutions of food systems during pandemics save time, money and provide food sources to everyone [17]. Technology is crucial if we want to optimize production of animals, their feed consumption, environmental system of animal farms and livestock products [18].

\section{Improved genetics and modern breeding technologies}

Modern breeding technologies can improve genetic potential of food animals and animal products. Current pandemic has shed light on the importance of such advances in all livestock fields [19]. An effective breeding strategy in food animals is one of the ways in which cattle breeders can be successful. In many under developed countries, cattle selection is usually traditionally performed with phenotypic observations. This choice is less efficient. This is evidenced by the self-sufficiency of meat which has not been announced since 2010. The mapping of Quantitative Trait Loci mapping - encoding the quantitative role of genetic loci in food animals - is expected to provide a more accurate selection process. Animal selection through genome selection begins with an understanding of genome mapping. Genome mapping is used to identify the location of genes, locus on chromosomes and mutations [20]. Quantitative Trait Loci or QTL is the locus that is mapped. Many of these characteristics are important, both economically and medically, such as resistance to diseases, meat and milk production. The basic concept in genomic selection is that single nucleotide polymorphisms (SNPs) are considered as a marker on the relationship between locus.

Next, identification or marking of SNPs can be done by identifying QTL locations in the genome for genetic mapping of species [21]. However, some simple markers can be used to understand the advantages and disadvantages of these markers. The precision of genomic selection depends on the distance of the marker with QTL, the process identification of phenotype, and the number of genes to be identified [22].

The flow of genetic mapping can easily be described as

- $\quad$ To use SNPs as markers, the genome needs to be read using microarrays. Unfortunately, the use of micro-arrays is less common in underdeveloped countries than the use of electrophoresis.

- Using a marker other than SNP would mean an easier flow, namely: DNA extraction - amplification of DNA by utilization of (polymerase chain reaction) PCR - electrophoresis using markers-Readout of results [23]. 
- $\quad$ The application of electrophoresis or micro-array imaging results in genome mapping.

This genome mapping can be used extensively in animal husbandry. In cattle meat, it can be used to evaluate and improve certain characteristics such as meat quality (water content in meat or juiciness, typical cow odor and protein content), feed efficiency ratio, resistance against parasites or certain diseases, heat resistance and other quantitative genetic characters [24].

Whereas in dairy cows, some of the characters that can be added are genes encoding bioactive substances on milk to be produced so that dairy products can be more nutritious [25].

Due to the limited supply of feed, animal feed management also needs to be prepared to deal with food safety. Safe production of animal feed is one of the most important method for the health and management of livestock. Genome mapping can also be done in animal feed plants. Selection through this genome can improve the accuracy of phenotype selection, which has been done extensively in Pakistan. Several parties can involve in the development of the livestock sector in Pakistan have been able to work together to obtain selective livestock genomes through the collection of integrated livestock genome data $[20,25]$.

Branding and digitalization of livestock products to overcome the decline in sales

In this pandemic, breeders and distributors of livestock products have to maintain cash flow to sustain their business [26]. Fortunately, livestock products can be marketed through remote interactions. This is supported by the guidance and research and provided by Widayat and his team. The study found that consumers between the ages of 15 and 25 buy food and ingredients prepared during pandemics online [27]. This can be done through the various platforms and communities that are formed on social media. Promotion media can be done by many people with a large number of followers or paid promotion on accounts with access to large media [28]. Promotional material in the form of a campaign to use nutritious livestock products during the current pandemic can be an interesting selling point. Processed food made from livestock products or local culinary products can be sold by this tricky way [29].

The second step is delivery services, which are very important in this situation. Delivery services can be made through form em- ployee courier or using campaign services, or it can also use ecommerce which provides delivery services and even free shipping coupons [30].

Easy access to product information, payment and product delivery can help propel the market forward to keep the business going during the lockdown [31]. Small-scale farms can encourage each other through collaboration to maximize their impact on improving livestock product development methods and marketing processes. It is expected that these two solutions will solve the problem of low market for livestock products and help in distribution of livestock products [29,31].

Practices and amenities for processing and marketing of Animal products

Improving the processing techniques and marketing facilities of animal products by increasing their distribution facilities and increasing the marketing force are necessary steps to prevent food shortage during lockdown and pandemics [32]. If the current lockdown lasts longer, then people will need animal products and by-products that are long-term stable, durable and have quality packaging [33]. Processed Livestock Product like meat which has high nutritional and water level, is the right medium for growing micro-organisms thus making it more susceptible to rot. Therefore, proper processing is much necessary. Because meat may store for longer durations in stores or at homes in lockdown situations [34]. To preserve meat through freezing, the meat is cooked with selected herbs and then packaged and frozen. Freezing techniques are also used mostly in indoor areas [35]. In addition, thermal processing and smoking products are used in other scales to avoid the damage caused by decaying conditions [36]. Processing techniques, flavoring skills and preservation techniques are key to improving the quality of livestock products $[37,38]$. The creative ability to make coffee flavor with milk can be an attractive product to increase sales during such pandemics. Some other preparations for milk processing such as doodle milk may be another option [39].

\section{The future of animal husbandry}

The complexity of these food issues requires a multifaceted and appropriate strategy for mutual cooperation. So that we can fight malnutrition during COVID-19 pandemics. After recovering from the current pandemic, we must better prepare for the future crisis $[40,41]$. The malnutrition warning alarm starts when one-third of the world's population experiences limited mobility [42]. The 
pandemic of COVID-19 will definitely reduce the attention of different countries on livestock health and production. The Food and Agriculture Organization (FAO) recommends that countries pay special attention to food and develop strategies to deal with it in order to create food safety during coronavirus emergencies. The long-term effects will need to be taken seriously. The livestock sector also supports success in meeting food security [43]. To improve the health of food animals especially during pandemics and during communicable health issues telehealth technologies should utilize proactively in livestock sector.

\section{Telehealth facility}

This is causing difficulties and delay in providing treatment to animals. By using telehealth facility this problem can be solved. Barriers in the use of telehealth at each community level should be solved as prime priority. Cases other than emergency situation can tackle easily from farmer's farm [45]. This way animals can remain safe and food resources will not decline. Government should prepare telehealth doctors force for livestock and related courses should be included in curriculum of veterinary education [46]. Telehealth is safe for doctors and it will also decrease the stress of farmers and their families [47].

\section{New policies regarding food resources management}

It is responsibility of political leaders and educational institutes to make such policies regarding food resources management for whole nation during pandemics [48]. We can't say anything about the occurrence of such pandemics in future. Because epidemics and pandemics are occurring from hundreds of years and we can't say anything even about COVID-19 reoccurrence in future [49]. But we can prepare public for such future crisis by improving our health facilities especially related to food animals. Because COVID-19 also has some origin from wet food market so directly involvement of animal health should concern first [50].

\section{COVID-19 vaccination preparation and use of animals}

Till new advances in developing vaccines against pandemics causing viruses. Scientists are using laboratory animals for vaccination trials [51]. Therefore new policies and guidelines are very necessary for lab or experimental animal health and production management. Industry and government co-ordination can solve such problems by collaborating with academic institutes [52].

\section{Role of veterinarians in meat markets}

Meat markets, where animals of different kinds (wild and domestic) are sold, are a main source of origin of zoonotic disease.
Many researchers have suggested that bats are reservoir hosts for many coronaviruses. Bats are asymptomatic to coronaviruses $[53,54]$. The SARS-CoV-2 was also transmitted between different species in wet markets in Wuhan. Therefore, these markets should be considered by veterinarians from a zoonotic point of view [55]. Such markets are not banned but with new rules and regulations we can regulate these markets. It is now imperative to reduce the likelihood of this pandemic occurring in the future in a collaborative process between veterinarians, doctors and environmental scientists nationally and internationally [56]. Because there is a direct relationship between humans, animals and their common environment [57]. Therefore, it is important for everyone's health to protect themselves from future outbreaks and pandemics, such as from SARS, MERS and COVID-19 like pandemics [58,59].

\section{Conclusion}

Based on the above explanation, the effects of COVID-19 have affected the livestock sector severely. This is evident from the poor condition of the livestock domain. In addition, the risk of future malnutrition and food shortage is also predicted. To solve these issues, farmers should be encouraged to increase the immunity of their domestic animals by adding micronutrients to their rations. It is important to avoid feed shortages in the future, especially during pandemics. Healthy eating and drinking food animals are a source of healthy meat and milk. Animal food shortages can be overcome by improving the genetics of animals and animal feed plants and incorporating unconventional feed resources into their diets. Telehealth or telemedicine facilities should be improved to provide proper treatment to the farmers in case of any kind of lockdown. Increase the number of meat and milk processing plants in all cities to provide permanent fresh food to the people during any future crisis. Increasing the value addition of livestock products can ensure an increase in income. Digitization in the livestock business will make it easier, faster and safer to sell and buy livestock products. This will be helpful, especially during infectious and contagious diseases pandemics. Online buying and selling, such as the use of information technology and computer science, can create new markets for livestock products and services by implementing the COVID-19 security protocol. Farm biosafety and biosecurity are essential to prevent infectious and zoonotic diseases. These suggestions can help academic researchers, food sector scientist and livestock sector to reduce losses and waste of food. New research is much needed to identify alternative safe sources of protein that can meet all kinds of nutritional needs of people in under-developed countries. 


\section{Bibliography}

1. Tesso, Gutu. "Review of the Impact of COVID-19 on Economic Growth, Unemployment and Progress out of Poverty in Ethiopia".

2. Djalante Riyanti., et al. "Review and analysis of current responses to COVID-19 in Indonesia: Period of January to March 2020". Progress in Disaster Science (2020): 100091.

3. Viner Russell M., et al. "School closure and management practices during coronavirus outbreaks including COVID-19: a rapid systematic review". The Lancet Child and Adolescent Health (2020).

4. Rasul Golam. "Managing the food, water, and energy nexus for achieving the Sustainable Development Goals in South Asia". Environmental Development 18 (2016): 14-25.

5. Galanakis Charis M. "The Food Systems in the Era of the Coronavirus (COVID-19) Pandemic Crisis”. Foods 9.4 (2020): 523.

6. Thornton Philip K. "Livestock production: recent trends, future prospects". Philosophical Transactions of the Royal Society B: Biological Sciences 365.1554 (2010): 2853-2867.

7. Deaton B James and Brady J Deaton. "Food security and Canada's agricultural system challenged by COVID-19". Canadian Journal of Agricultural Economics/Revue canadienne d'agroeconomie (2020).

8. Galanakis Charis M. "The Food Systems in the Era of the Coronavirus (COVID-19) Pandemic Crisis”. Foods 9.4 (2020): 523.

9. Monchatre-Leroy Elodie., et al. "Identification of alpha and beta coronavirus in wildlife species in France: bats, rodents, rabbits, and hedgehogs". Viruses 9.12 (2017): 364.

10. Grace Delia EA., et al. "Optimizing livestock farming in urban agriculture". Burleigh Dodds Science Publishing (2020).

11. Mhlanga David and Emmanuel Ndhlovu. "Socio-economic Implications of the COVID-19 Pandemic on Smallholder Livelihoods in Zimbabwe". (2020).

12. Thornton Philip K. "Livestock production: recent trends, future prospects". Philosophical Transactions of the Royal Society B: Biological Sciences 365.1554 (2010): 2853-2867.

13. Henchion, Maeve., et al. "Future protein supply and demand: strategies and factors influencing a sustainable equilibrium". Foods 6.7 (2017): 53.
14. Boland, Mike J., et al. "The future supply of animal-derived protein for human consumption". Trends in food Science and Technology 29.1 (2013): 62-73.

15. Osterhaus Albert DME., et al. "Make science evolve into a One Health approach to improve health and security: a white paper". One Health Outlook 2 (2020): 1-32.

16. Bishwajit, Ghose., et al. "Trade liberalization, urbanization and nutrition transition in Asian countries". Journal of Nutrition and Food Sciences 2.1 (2014): 5.

17. Dalvit C., et al. "Genetic traceability of livestock products: A review”. Meat Science 77.4 (2007): 437-449.

18. Samarin Gennady N., et al. "Optimization of microclimate parameters inside livestock buildings". International Conference on Intelligent Computing and Optimization. Springer, Cham (2018).

19. Xu Yunbi., et al. "Enhancing genetic gain through genomic selection: from livestock to plants". Plant Communications 1.1 (2020): 100005.

20. Xiong Jin. Essential bioinformatics. Cambridge University Press (2006).

21. Mrode Raphael., et al. "Genomic selection and use of molecular tools in breeding programs for indigenous and crossbred cattle in developing countries: current status and future prospects". Frontiers in Genetics 9 (2019): 694.

22. Semagn Kassa., et al. "Principles, requirements and prospects of genetic mapping in plants". African Journal of Biotechnology 5.25 (2006).

23. Gutiérrez-Gil., et al. "Genetic effects on coat colour in cattle: dilution of eumelanin and phaeomelanin pigments in an F2Backcross Charolais $\times$ Holstein population". BMC Genetics 8.1 (2007): 56.

24. Jensen Robert T and Nolan H Miller. "Do consumer price subsidies really improve nutrition?". Review of Economics and Statistics 93.4 (2011): 1205-1223.

25. International Barley Genome Sequencing Consortium. "A physical, genetic and functional sequence assembly of the barley genome". Nature 491.7426 (2012): 711-716.

26. Widayat Widayat. "Attitude and Behavior to Eating in the Time of COVID-19; A Case Study of Adolescent Consumer in Indonesia”. Jurnal Inovasi Ekonomi 5.2 (2020). 
27. Kirtiş A Kazım and Filiz Karahan. "To be or not to be in social media arena as the most cost-efficient marketing strategy after the global recession". Procedia-Social and Behavioral Sciences 24 (2011): 260-268.

28. Salomonsson Karin. "The E-economy and the Culinary Heritage”. Articulating Europe: Local Perspectives 32 (2003): 125.

29. Heath Stephan. "Mobile device system and method providing combined delivery system using 3D geo-target location-based mobile commerce searching/purchases, discounts/coupons products, goods, and services, or service providers-geomapping-company/local and socially-conscious information/social networking ("PS-GM-C/LandSC/I-SN")". U.S. Patent No. $10,140,620$ (2018).

30. Pueyo Tomas. "Coronavirus: Why you mustactnow". Politicians, community leaders and business leaders: what should you do and when (2020).

31. Shaner Willis W. "Farming systems research and development: Guidelines for developing countries”. Routledge (2019).

32. Galanakis Charis M. "The Food Systems in the Era of the Coronavirus (COVID-19) Pandemic Crisis”. Foods 9.4 (2020): 523.

33. Khan Naushad., et al. "COVID-2019 Locked down Impact on Dairy Industry in the World". SSRN Electronic Journal (2020).

34. Pal M and M Devrani. "Application of various techniques for meat preservation". Journal of Experimental Food Chemistry 4.134 (2018): 2472-0542.

35. Rahman Mohammad Shafiur and Conrad O Perera. "Drying and food preservation". Handbook of food preservation. Marcel Dekker, New York (1999): 173-216.

36. Karoui Romdhane and Josse De Baerdemaeker. "A review of the analytical methods coupled with chemometric tools for the determination of the quality and identity of dairy products". Food Chemistry 102.3 (2007): 621-640.

37. Robinson Richard K., et al. "Microbiology of fermented milks". Dairy Microbiology Handbook: The Microbiology of Milk and Milk Products (2002): 468.

38. Chelule P K., et al. "Advantages of traditional lactic acid bacteria fermentation of food in Africa". Current Research, Technology and Education Topics in Applied Microbiology and Microbial Biotechnology 2 (2010): 1160-1167.

39. Dixon John A., et al. "Farming systems and poverty: improving farmers' livelihoods in a changing world". Food and Agriculture Org (2001).
40. Galli Francesco., et al. "Better prepare for the next one. Lifestyle lessons from the COVID-19 pandemic". Pharmanutrition (2020).

41. Holmes Emily A., et al. "Multidisciplinary research priorities for the COVID-19 pandemic: a call for action for mental health science". The Lancet Psychiatry (2020).

42. Galanakis Charis M. "The Food Systems in the Era of the Coronavirus (COVID-19) Pandemic Crisis”. Foods 9.4 (2020): 523.

43. Rosegrant Mark W and Sarah A. Cline. "Global food security: challenges and policies". Science 302.5652 (2003): 1917-1919.

44. Malhotra Dr. "Managing Agricultural Supply Chains in COVID-19 Lockdown" (2020).

45. Au Sunny Chi Lik. "Revisiting the role of telemedicine under the 2019 novel coronavirus outbreak". European Journal of Geriatrics And Gerontology 2.1 (2020): 26-27.

46. Smith Anthony C., et al. "Telehealth for global emergencies: Implications for coronavirus disease 2019 (COVID-19)". Journal of Telemedicine and Telecare (2020): 1357633X20916567.

47. Zhou Xiaoyun., et al. "The role of telehealth in reducing the mental health burden from COVID-19". Telemedicine and $e$ Health 26.4 (2020): 377-379.

48. Moon Suerie., et al. "Will Ebola change the game? Ten essential reforms before the next pandemic. The report of the HarvardLSHTM Independent Panel on the Global Response to Ebola”. The Lancet 386.10009 (2015): 2204-2221.

49. Yang Yongshi., et al. "The deadly coronaviruses: The 2003 SARS pandemic and the 2020 novel coronavirus epidemic in China". Journal of Autoimmunity (2020): 102434.

50. Sun Jiumeng., et al. "COVID-19: epidemiology, evolution, and cross-disciplinary perspectives". Trends in Molecular Medicine 26.5 (2020): 483-495.

51. Ahmed Syed Faraz., et al. "Preliminary identification of potential vaccine targets for the COVID-19 coronavirus (SARSCoV-2) based on SARS-CoV immunological studies". Viruses 12.3 (2020): 254.

52. Malhotra. "Managing Agricultural Supply Chains in COVID-19 Lockdown". SSRN 3602574 (2020).

53. Daszak Peter., et al. "A strategy to prevent future epidemics similar to the 2019-nCoV outbreak". Biosafety and Health 2.1 (2020): 6-8. 
54. Tiwari R., et al. "COVID-19: animals, veterinary and zoonotic links". The Veterinary Quarterly (2020): 1.

55. Leach Melissa and Ian Scoones. "The social and political lives of zoonotic disease models: narratives, science and policy". Social Science and Medicine 88 (2013): 10-17.

56. Almendros Angel. "Can companion animals become infected with Covid-19?”. Veterinary Record 186.12 (2020): 388-389.

57. Shetty P. "From food security to food and nutrition security: role of agriculture and farming systems for nutrition". Current Science (2015): 456-461.

58. Thornton PK. "Livestock production: recent trends, future prospects". Philosophical Transactions of the Royal Society B: Biological Science 365.1554 (2010): 2853-2867.

59. Alonso S., et al. "The role of livestock products for nutrition in the first 1,000 days of life". Animal Frontiers 9.4 (2019): 24-31.

\section{Assets from publication with us}

- Prompt Acknowledgement after receiving the article

- Thorough Double blinded peer review

- Rapid Publication

- Issue of Publication Certificate

- High visibility of your Published work

Website: www.actascientific.com/

Submit Article: www.actascientific.com/submission.php

Email us: editor@actascientific.com

Contact us: +919182824667 